Research, part of a Special Feature on Social Learning in Water Resources Management

\title{
Illuminating the Possibilities for Social Learning in the Management of Scotland's Water
}

\author{
$\underline{\text { Ray Ison }}^{1}$ and Drennan Watson ${ }^{2}$
}

\begin{abstract}
Our research explores the context of water management in Scotland as it existed in late 2003. We took as a key question: Is the Scottish policy context conducive to the emergence of "social learning" as a purposeful policy option in the future management of water, and in the implementation of the European Water Framework Directive in particular? Data generated by several means, including semistructured interviews with key stakeholders, tested the explanatory potential of a SLIM (Social Learning for the Integrated Management and sustainable use of water) heuristic concerned with how changes in understanding and practices can transform situations to produce social learning. Our research demonstrates how the historical context, including initial starting conditions; conducive institutions, especially political devolution, and policies; facilitation; building stakeholding; and the use of learning processes together can create the possibilities for social learning. The processes that went on through the development of the Scottish Water Bill exemplify how social learning as concerted action emerged, but it did not do so from any overall purposeful design. A major challenge is to create purposefully the conditions for social learning as a deliberate policy or governance mechanism.
\end{abstract}

Key Words: water framework directive; understandings; practices; SLIM heuristic; purposeful design; Scotland

\section{INTRODUCTION}

We present the results of research undertaken as part of the SLIM (Social Learning for the Integrated Management and sustainable use of water) Project funded under the European Union (EU) Fifth Framework (SLIM Project 2004a). For our purposes, social learning is defined as achieving concerted action in complex and uncertain situations. The overall focus of the SLIM Project was to understand the application of social learning as a conceptual framework, an operational principle, a policy instrument or governance mechanism, and a process of systemic change. Social learning in recent years has attracted interest as another way of conducting public business, alongside regulation, compensation, stimulation, and the operations of the market. It has also been promoted as essential for the management of complex natural resource dilemmas and a key process in adaptive management (Röling and Wagemakers 1998, Leeuwis and Pyburn 2002). A premise of SLIM research is that it is useful to view sustainability as an emergent property of stakeholder interaction and not as a technical property of the ecosystem; from this perspective, stakeholder interaction is not causal, i.e., it is necessary but may not be sufficient for sustainability outcomes to appear.

The initial SLIM research methodology was based on a simple logic derived from earlier research and the literature (Ison et al. 2007). The basic assumptions of this logic are that (1) designated stakeholders engage in (2) desirable practices that require (3) learning based on (4) facilitation made possible by (5) institutional support embedded in a (6) conducive policy context. This logic, which structured the research design, arose from earlier research by SLIM members that highlighted the inadequacy of linear models of technology transfer for generating behavior change to address complex natural resource issues (Röling and Wagemakers 1998, Ison and Russell 2000). Experience with farmer field schools in Indonesia in particular (Van de Fliert 1993) had highlighted how farmers had to act in concert, as in an effective performance that 
requires learning together, to effect integrated pest management in a given area. Achieving concerted action appeared to require attention to certain factors, i.e., (1) through (6) above.

This set of factors became the SLIM variables around which the conduct of both SLIM and case study research was designed. This structure was useful in that it provided entry points for the research and suggested a search for systemic coherence in complex situations. The comparative case studies (SLIM Project 2004a) sought to follow this logic in terms of case study choice and research approach, but did not follow ex ante blueprints. As seen in Figs. 1 and 2, this original heuristic informed our research design and evolved into a new heuristic, the SLIM framework, based on our research findings (SLIM 2004b, Steyaert and Jiggins 2007).

The case study reported here is one of 13 undertaken in the project (SLIM Project 2004a). In this study, we explore the context of water management in Scotland in late 2003. Early in the SLIM Project it became apparent that an important variable was missing from the original research design, namely, the history of the situation. Recognition that this was missing came from systems-theoretical understandings about the importance of initial starting conditions to any process as well as the recognition that exploring the context is an important initial step in any process of environmental decision making (Blackmore and Morris 2001). Context includes appreciating the history of situations of complexity and uncertainty associated with multiple stakeholders (SLIM Project 2004b).

In this case, our research took as a key question: Is the Scottish policy context conducive to the emergence of social learning as a purposeful policy option in the future management of water, and in the implementation of the European Water Framework Directive (WFD) in particular? By framing the research in this way, we were explicitly attempting to identify emergent themes and subthemes as well as examine the explanatory power of the SLIM variables (Fig. 2). A similar case study was undertaken in England and Wales (Blackmore et al. 2004). In answering this question we recognized the following contextual issues:

- the Scottish policy context is dynamic, and our research could only give a picture at a moment in time;
- at the time of our research, the Water Environment and Water Services (Scotland) Act had just been enacted, so that, unlike the rest of the UK, the WFD had been transposed into Scottish Law;

- despite the dynamic policy context, there were likely to be trends and patterns that reflect deeper theoretical and structural issues that persist over time;

- water policy in Scotland is systemically connected to international water policy, European water policy, and UK water policy but also has distinctive features that are a direct result of the history of water management in Scotland, including particular institutional (sensu North 1990) lineages;

- policy is not isolated theoretically from institutional factors, and a particular policy is one example of an institutional factor; and

- we take the perspective that policy does not exist in isolation from its enactment, so that policy is also a form of praxis.

The introduction into national law of the European WFD and the requirement for public participation in its implementation added relevance to our research because of the constantly changing context (see Kaïka 2003, Kaïka and Page 2003, Page and Kaïka 2003, Stayaert and Jiggins 2007).

In seeking to further test and refine the SLIM heuristic, we did not attempt to illuminate each of the variables in a systematic manner but examined their validity, or lack thereof, in explaining what were elicited as themes and subthemes from the interviews and desk research. A set of policy briefings explaining the nature and significance of each of the variables as well as guidelines have been developed; all these documents are available on the Web (http://slim.open.ac.uk). It is important to note that the systemic coherence of these variables emerges first through learning processes, which are not explicit in the figures, in which changes in understanding accompany changes in practices and, second, through the way in which the heuristic is used, i.e., diagnostically, analytically, or facilitatively (SLIM Project 2004b). 
Fig. 1. Situations of complexity, uncertainty, and conflict associated with water management are transformed through concerted action by stakeholders, who build their stakeholding in the process. This leads to changed understandings, i.e., knowledge in action, and practices.

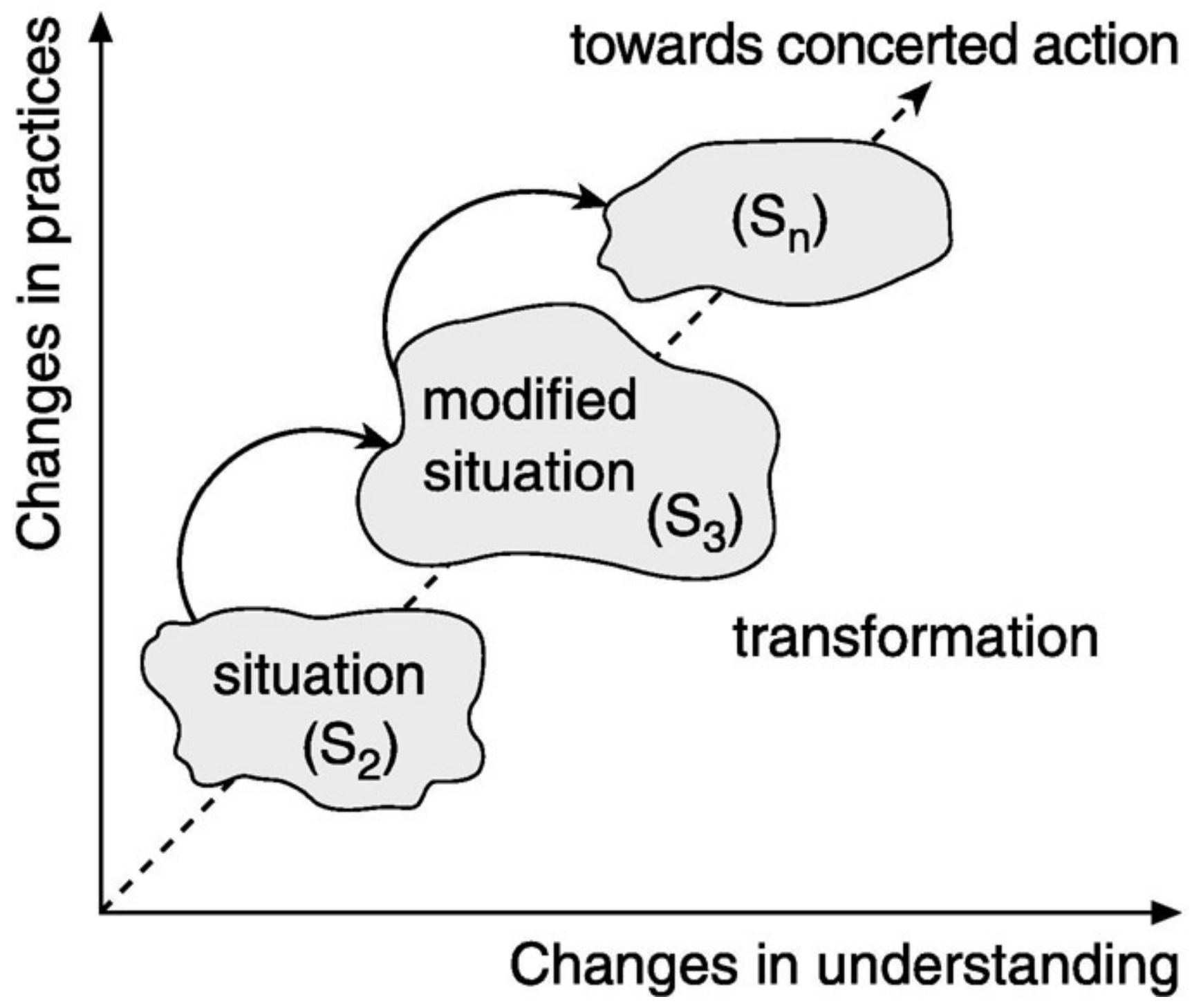


Fig. 2. In the SLIM (Social Learning for the Integrated Management and sustainable use of water) research, we have been concerned in particular with how six variables interact and are mediated by learning processes to shape issues and transform particular situations. These variables include history, stakeholding, facilitation, institutions and policies, and ecological constraints.

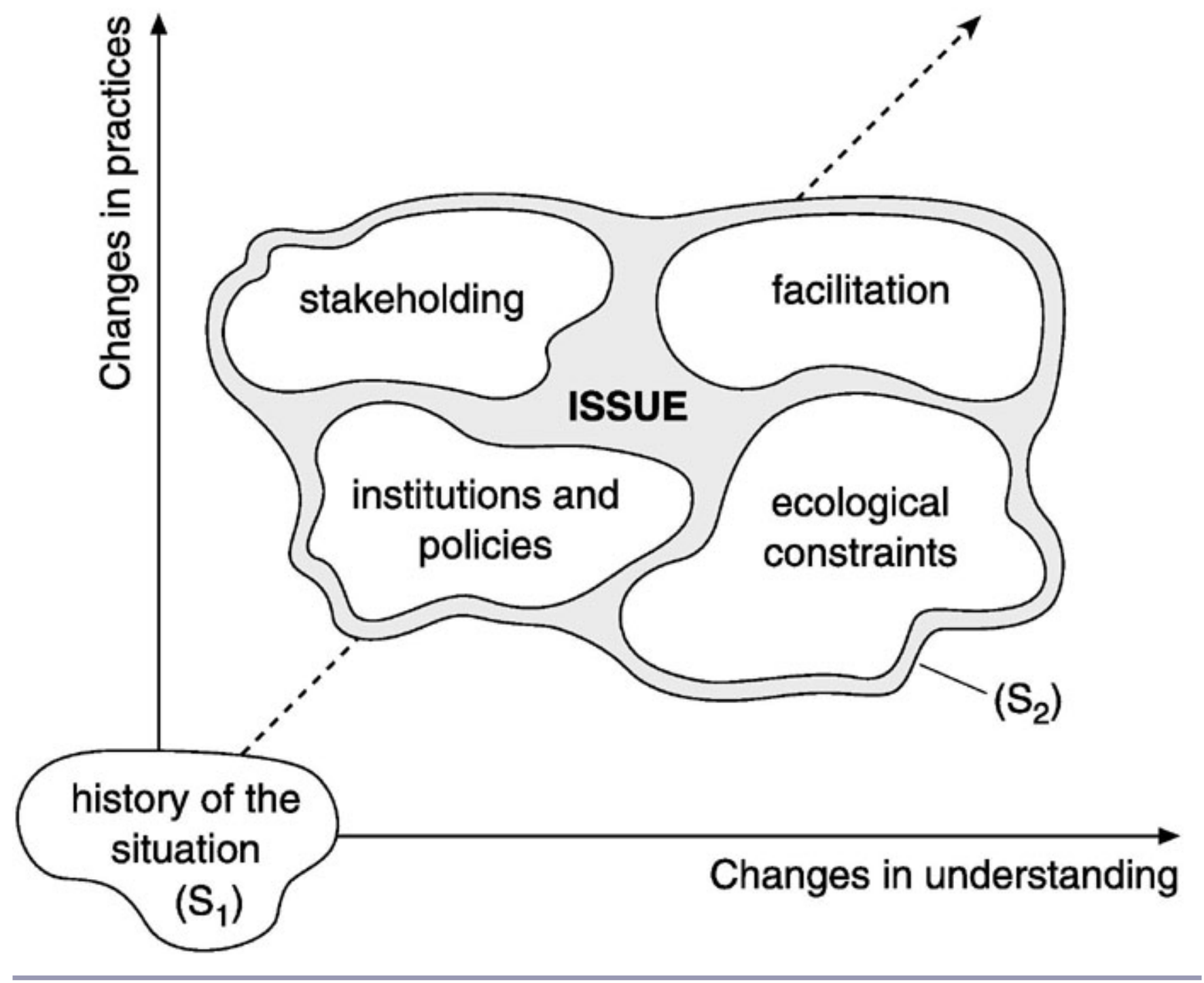




\section{METHODS}

\section{Research events}

The research comprised (1) desk study, (2) semistructured interviews, (3) participant observation in three workshops and one conference, and (4) informal discussions with key informants. Semistructured interviews were carried out with 21 people, of whom eight were interviewed individually. Details of the interview process and those interviewed can be found in Appendix 1. The period of data gathering for the case study for the full range of data sources extended from January to October 2003.

\section{Data analysis}

Analysis of the data followed the guidelines described by Patton (1987) and also drew on processes associated with grounded theory (Glaser and Strauss 1967), although not grounded theory development per se. The basic technique of grounded theory research, i.e., working through the data systematically, categorizing, developing core categories and abstracting definitions, following through on particular themes that relate to the core categories, and noting possible theoretical ideas as the data are sifted, read and reread, describes the main method of analysis. However, not all categories arose from the ground up; the SLIM research design had established a set of key variables that appeared to be present when social learning emerged in situations of natural resource management (Fig. 2). These were incorporated into the evolving SLIM heuristic (SLIM 2004b) and guided the analysis.

\section{RESULTS AND DISCUSSION}

\section{Summary of the main themes and subthemes}

Appendix 2 presents the main themes and subthemes that emerged from the data analysis and, where relevant, their relationship to the SLIM (Social Learning for the Integrated Management and sustainable use of water) heuristic (Figs. 1 and 2); Ison and Watson (2004) elaborate more fully on these. Because it is not possible to present all of our results in this paper, we choose to present two themes. We first consider the variable that represents the history of the situation (Fig. 2) based on the outcomes of the desk study and interviews. Within this, we include aspects of the Water Framework Directive (WFD) particular to the Scottish context. We then report on the narrative associated with the development and introduction of the Scottish Water Bill, i.e., the "bewitching" of the Scottish Water Bill, because it allows us to explore and assess all of the SLIM variables; it also suggests what might be possible through awareness of, and investment in, social learning.

\section{History of the situation}

Water management in Scotland differs from that in England and Wales for two major reasons. One is that a condition of the Union of Parliaments in 1707 was that Scotland was to retain many of its separate institutions of government, so that separate legislation had to be passed for England and Wales on the one hand and Scotland on the other. The second reason relates to the differences in geology, topography, population, and culture.

Scotland covers $78,703 \mathrm{~km}^{2}$. The average rainfall in Scotland is $1431 \mathrm{~mm} / \mathrm{yr}$, but this conceals a steep gradient of high rainfall in the west, which can receive $270 \%$ of this average, in contrast to the east coast, which often receives only $40 \%$. The topography differs greatly from that of England. Much of the main divide runs close to the western coast where the rain-bearing winds of the west and southwest deposit heavy orographic rain, whereas the 17 larger catchments drain mainly to the east in surprisingly long and large rivers for such a small country. There are 31,469 freshwater lakes or lochs. There are about 780 islands, about half of them inhabited, and this and the much indented coast give the country some $12,000 \mathrm{~km}$ of coastline.

Scotland holds $90 \%$ of all the freshwater resources of the UK, $66 \%$ of which are found in the Scottish Highlands alone, where they have been heavily exploited for hydropower. Historically, the main problems of water management have been pollution by domestic and industrial use, diffuse pollution from agriculture, acidification, urban drainage and pollution derived from it, and, to a lesser extent, drainage water from deep mines and point-source pollution from agriculture (Appendix 2). More recently, as some of these problems have been mitigated, flooding and possibly water shortage through drought have emerged as problems attributable, it is thought, to climate change. 
Each of these factors has implications for how water can be managed if an integrated catchment management approach is desired.

\section{Contemporary political and institutional structures}

Until 1996, the supply of water for domestic and industrial use was the responsibility of local government, in this case 53 District Councils under a two-tier system of local government in which nine Regional Councils oversaw more strategic issues. The plentiful local supplies of water made it possible for management and supply to be handled at this level. An exception was the creation of the Central Scotland Water Board in 1967 to deal with the concentration of the population in the central lowlands. The difference in overall population densities between Scotland and England and Wales (62 individuals $/ \mathrm{km}^{2}$ vs. $320 / \mathrm{km}^{2}$ ) also aided this arrangement. In 1989, an attempt by a Conservative government to privatize water supplies, as had been done in England, was so strongly opposed by the population in what is inherently a more collective society that it was dropped. Three River Purification Boards responsible for reducing freshwater pollution covered the entire country, and their efforts led to major improvements in freshwater quality in rivers, streams, and lochs.

In 1996, under the Local Government Act (1994), the two-tier system of local government was simplified to 32 single local government authorities. Responsibility for the provision and treatment of domestic and industrial water supplies was transferred to three water authorities. In the same year, under the Environment Act (1995), the River Purification Boards were merged and transfered to a new body called the Scottish Environment Protection Agency (SEPA), which was also responsible for controlling air pollution, waste, and radioactive substances and for integrated pollution control.

This is very much the situation today except for two important changes. In 2003, the three water authorities were merged into one body, Scottish Water. Second, the Natura 2000 program under the European Union's Habitat Directive and Birds Directive led the Scottish wildlife protection agency, Scottish Natural Heritage (SNH), to start to designate numerous water bodies as protected areas. This has included two of the largest rivers, the Dee and the Spey. Because the Water Framework Directive states that, within Natura 2000 sites, the ecological standards to be achieved are those of the Natura 2000 legislation, this gives SNH a significant role in their management. For example, SNH has been made the lead agency in the preparation of the catchment management plans for the rivers Dee and Spey.

This institutional and organizational history highlights the understandings that might be needed to facilitate multiorganization cooperation in managing water.

In 1999, a new Scottish parliament was created with considerable devolved powers. This permitted a greater focus on specifically Scottish situations within the law-making process, particularly because the greater powers and role of subcommittees of parliament in the Scottish system encourage greater participation by stakeholders. In January 2003, the parliament passed the Water Environment and Water Services (Scotland) Act in response to the Water Framework Directive. The structure of the parliament has encouraged legislators to take a more holistic approach to the management of water under this bill than under the equivalent act for England and Wales (see below). The Scottish Executive, which includes ministers and the civil servants of the former Scottish Office, is one of the major players in the policy process. The Executive is still evolving institutionally from the old Scottish Office. Within the Executive, the Scottish Executive Environment and Rural Affairs Department is responsible for advising ministers on policy related to agriculture, rural development, food, the environment, and fisheries and for ensuring the implementation of those policies in Scotland.

Devolution significantly changed extant power relations. For example, landowning and salmon fishing rights were historically vested in a small and elite group represented in the House of Lords in Westminster. For centuries they used this position to influence legislation affecting their interests. As one interviewee described it: “... there used to be a hotline between those interests in Scotland and the House of Lords, so any relevant legislation got the House of Lords' scrutiny, and, if it threatened their interests, they would get down there and defeat it" (Interview SPC3 according to the code used by the SLIM Project to identify its interviews while allowing the subjects to remain anonymous). This has now changed with the reform of the House of 
Lords and devolution to Scotland. Interviewees reported a new, emerging dynamic involving government departments giving money to shape policy: "The national parks, the access to countryside element of the land reform, have been two very big examples, quite substantial steps forward" (Interview SPC3). In fisheries management, research, and development, the historical focus in Scotland had always been on salmon, but a number of interviewees related how the balance was now changing to incorporate coarse fishing and a wider range of species: "The Labour Government and Scottish Executive have taken the view that we haven't done enough in the past to look at coarse fish" (Interview SPC5a). These changing power relations were effectively exploited by the NGOs (see below).

Different organizational arrangements persist for the management of drinking and surface water quality associated with the former Water Purification Boards, now incorporated into SEPA, and the old water authorities, which are now part of Scottish Water; this presents a particular challenge for inter- and multiorganizational working.

Appreciating this history highlights how the arena for policy development, or policy as praxis, is changing. Central to this evolving dynamic are new institutional arrangements.

\section{Introducing and implementing the Water Framework Directive}

In Scotland, implementation of the WFD is guided by the legislation that transposed the Directive into Scottish Law, even though it is the UK as a whole that has to report to the EU and will be guilty of any infractions that arise. In the first phase of WFD implementation, river basin districts (RBD) had to be specified (see Ollivier et al. 2007). In Scotland, SEPA were intimately involved, especially in the early requirement for characterization of waterways and in preliminary mapping and planning for designating RBDs. In contrast to the Environment Agency (EA) in England and Wales, SEPA were designated as the lead authority rather than the competent authority; this is a significantly different institutional arrangement, as we discuss below.

In the early stages of implementing the WFD in both England and Scotland, the idea that the WFD is not "gold-plated" emerged. "There was all the talk of gold-plating going on, and everybody saw it [the
WFD] purely as a regulatory thing. You know, the River Basin Management Plan will be the vehicle to implement the rules that landowners will have to follow or they'll get fined ... at the beginning, it was very much seen as that, [but after] further Parliamentary process ... it was [a] wider principle" (Interview SPC8).

The metaphor reflected a decision made in Whitehall that the WFD be implemented with no extra expenditure. Within the Scottish Executive, the gold-plating metaphor was well understood. It was suggested that "we have a history where we would prefer not to gold-plate a directive because it would produce additional costs on various sectors. However, I think in this instance ... it was seen as an opportunity to improve the environment and there are differences of interpretation between what DEFRA [the Department of Environment, Food and Rural Affairs in England] would consider to be goldplating, and what we consider to be valid improvement to the environment!" (Interview SPC13a). In other words, this was another example of new Scottish independence in the policy development process.

In almost all the interviews, the respondents spoke positively about the new bill. There was a strong sense that Scotland had "taken the nettle by the hand" (Interview SPC1). Respondents indicated that (1) there was the necessary political will and leadership to get the act passed and to make it a good act, and (2) there was a desire to learn from past mistakes such as infractions and related fiscal and legal penalties associated with implementing the EU Nitrates Directive. "Diffuse pollution from farming and Nitrate Vulnerable Zones had 'blown up' and become 'a huge farce' ... [and the Executive was] being criticized for not having implemented [the Nitrates Directive] for 11 years" (Interview SPC8). There were, however, different perspectives and contested positions; an alternative view was that "the changes in legislation in Scotland are really just to bring them up to, on a parity with everything else that exists in England and Wales" (Interview SPC5a).

Against this backdrop, our research revealed an example of social learning, understood as concerted action among diverse stakeholders. 


\section{The "bewitching" of the Scottish Water Bill}

The Scottish Water Bill (SWB), officially the Water Environment and Water Services (Scotland) Act (2003), was a product of the way in which the Scottish Parliament works, of leadership and facilitation by key individuals in the Scottish Executive, of critical input from the Scottish Parliamentary Information Office, and of the effective intervention and facilitation by three NGO staff acting under the auspices of Scottish Environment Link (SEL). Through their active involvement in the process of developing this bill, these three staff members, all of them women, became known as the "three witches," a title granted with the greatest respect, possibly because of the "bewitching" effect they had on the overall process. The story told here about this group is filtered through the lens of the SLIM heuristic (Fig. 2).

NGOs were involved from an early stage, but the SWB “...started off with a very classic consultation ... in September 2001" (Interview SPC8). Consultations of this type are the most common way to start off environmental decision making in the UK at the present time; Ison et al. (2006) give examples and draw attention to the implications of starting off through consultation or participation.

\section{Stakeholders and stakeholding}

Stakeholders are those who have a stake, i.e., a real, material interest from their perspective, in the situation or in the resource under consideration (SLIM Project 2004c). Stakeholding expresses the idea that individuals actively construct, promote, and defend their stake, although, through their engagement with an issue, their understanding, and thus their stake, may change, giving rise to new practices (Fig. 2). In this example, the NGO staff quickly became concerned about the lack of stakeholder response to the consultation exercise and proposed a series of public seminars. "[W]e'd met the Executive and said, 'Look there's a lot of ideas to be developed here, we need some open debate. Can we run a series of three seminars with you before Christmas to get some [different stakeholders] involved in discussing issues?' And we identified a number of different issues, wetlands was one of them." Initially, wetlands had not been seen as relevant. It was then suggested that diffuse pollution, participation, and policy integration be the focus of seminars (Interview SPC8). After discussions with Scottish Executive officials, stakeholder seminars were held.

A conclusion reached by the NGO staff from this early stage was that, for effective consultation, there is a need to first make sure that all people "have the basic knowledge" (Interview SPC8) to be able to participate; to put it another way, people need the capacity to express their stakeholding in issues (SLIM Project 2004c). Also, " they must see the relevance of what is being proposed to their lives" (Interview SPC8). In the case of the water bill, this was achieved by fostering several conversations and taking a step back and involving stakeholders in discussions about what should be in the legislation, rather than just presenting a draft bill. This enabled people "to get more of a handle on the issues" (Interview SPC8ab). Thus, in theoretical systems terms, the initial starting conditions were changed by creating new boundary conditions.

Facilitation in the form of seminars, personal contacts, and Web reporting was used to actively build stakeholding in the process of drafting the Scottish Water Bill.

\section{Facilitation}

Facilitation is a key SLIM variable (Fig. 2; SLIM Project $2004 d$ ). In this example, facilitation was apparent in a number of ways. The SWB was introduced to Parliament in May/June 2002. The SEL members "held an event in a café for MSP [members of the Scottish Parliament] researchers, others, and Scottish Parliament Information Centre researchers and the Clerks of the Committee to come along and get a bit of our perspective on what we thought of the draft bill they introduced to Parliament ... we had a guy over from WWF [World Wildlife Fund] Denmark who did a presentation on the participation angle and we had a bit of a general discussion about the other stuff, and we had some insurance people there [these were to have a significant impact]... " (Interview SPC7). Facilitation thus extended to summarizing and critically appraising the draft bill, feeding back comments, and creating a social milieu in which effective relationships could be built.

The NGOs took their facilitation role further: "at the end of the summer before we went to Parliament, we [extended] an invitation to all committee member clerks and the Scottish Parliament 
Information Centre Staff, the researchers who were working on the bill to come up to Insh Marsh (see http://www.kincraig.com/rspb1.htm). There is a[n] RSPB [Royal Society for the Protection of Birds] Reserve up there, a Wetland in Action, and we [went] up, a minibus full, I think three or four MSPs and some researchers and a couple of clerks up there at the end of the summer..." (Interview SPC7). This initiative was to prove a significant learning experience for those involved and was pivotal in expanding the bill to include wetlands (see Appendix 3).

The three witches played an important facilitation role, but they were not the only ones. Individuals from the Scottish Parliament Information Office also played an important facilitation role, introducing key concepts and Australian experience among other things. They also changed their own customary practices as NGO advisors by providing a briefing on specific areas of the bill, such as participation, rather than their usual overall briefing on a bill. Gender and individual personalities may have been other factors.

\section{Conducive institutions: the legislative process}

The particulars of the Scottish legislative process were critical to the "bewitching" process (Appendix 4). In this situation, the NGOs organized and adopted what was for them a novel approach to dealing with the issues: one NGO focused on integrated policy, one on participation, and one on natural solutions and wetlands. This was the first time they had worked in concert rather than in parallel.

The committee structure in the Scottish Parliament was significant in the construction of the SWB. Parliamentary committees are involved throughout the progress of a bill. Scotland, unlike the parliament at Westminster, has proportional representation, which results in more minority parties being represented in the parliament and hence within the parliamentary committee structure. These have " ... made the process of any legislation a lot easier to access for well organized and interested NGOs, or for others like the Scottish water industry or the bottling industry, the distilling industry ... [whereas] in the early $80 \mathrm{~s}$, late $90 \mathrm{~s}$, we [NGOs] hardly had a look-in because anything that we might want to say direct to Westminster had to go via the Scottish Office in Edinburgh, whereas now we've got a locally accountable parliament, and it's a smaller world that we're dealing with" (Interview SPC3).

The NGO group was particularly effective during the committee stages. For example, the NGO perspective was that "participation structures integration ... [and] there was an amendment with Fish Farming, which we've been pushing for, and this was an ideal vehicle for it, and the Executive resisted it. Largely, I think, because the Department [in the Scottish Executive] who would draw it up were a different part from [those] doing Water Environment, it was a planning amendment. In the end, pressure brought them together, and they made an amendment" (Interview SPC7).

The key conducive institutional arrangement (see SLIM Project 2004e) in this narrative is the committee structure of the new Scottish Parliament, which enables a wider range of perspectives to be drawn into the policy and legislative process. This, however, was not enough; the existence of a networking organization, the Scottish Environmental Link, provided an effective platform for a team approach to be developed to create and respond to openings in the legislative process. The practices of the three witches built relational capital, which is discussed in Appendix 5 and SLIM Project (2004f).

\section{Learning processes, relational capital, and social} learning

The first stages of building relational capital can be seen from an early critical incident in the process. "[W]e took X [from the Executive] for a beer after one of those seminars ... I think the Executive had a real perception that Link were just having a go at them, they were just being quite aggressive. I think they were used to NGOs being quite aggressive ... I think it took a while to get a feeling that we were actually working with them. [After that] they'd be calling us up and finding out what we think about things before we' $d$ responded. We'd be asking [for] certain information ... [and] by the time the bill came out we were working really well with them" (Interview SPC8a). The attitude in the Executive was characterized as changing from what they could get away with to what they actually needed to do. This indicates that enacting the bill became more like a joint enterprise (Wenger 1998), suggesting this is one of the key ways to build relational capital and the beginnings of a community of practice. 
From our perspective, the NGOs, by intervening to change the boundary judgments around the SWB as a system of interest, opened up further spaces for learning. "We were using language in our briefings like, 'Yeah, these things are welcomed, but we don't feel that the Sustainable Development remit of this Directive will be fulfilled by Scotland if XYZ isn't done,' so we were effectively saying, 'We won't be transposing the Directive fully enough unless we take a wider approach and unless these different things can be addressed as well" (Interview SPC8b). In systemic terms, this is a shift in level of abstraction or system level, i.e., changing from considering it as if it were "a system to manage water" or "a system to implement the WFD" to "a system to manage sustainable development." We suggest that those responsible for natural resources policy in the UK suffer from an inability to conceptualize policy in these terms. They might be well advised to consider the experiences of the Department for International Development and their move to a livelihoods strategy as opposed to more sectoral concerns (see Mehta et al. 1999).

A number of experiential learning events were planned by the three witches for key stakeholders; these are described in Appendix 3, although interviewees did not speak in terms of learning. Key considerations were the desire to elicit different perspectives, a key element of systems practice (The Open University 2004), and effective dialogue. In relation to the SLIM heuristic, we conceptualize learning processes (see SLIM Project 2004g) among stakeholders as mediating the transformation process toward social learning, e.g., facilitation can be an important aspect of a particular learning process, but in itself may not lead to social learning.

\section{Changes that were achieved: transforming the situation}

The evidence supports the claims that NGO involvement and facilitation led to significant changes in the structure and content of the SWB. The main transformations achieved were to:

1. successfully challenge the definition of the "water environment" as defined in the act so as to include significant wetlands. Through this action, they changed the boundary of the water system as enshrined in the SWB; this clearly resulted from changes in understanding and practices and in turn has and will lead to new practices (Figs. 1 and 2). It also involved skilled negotiation, which can be seen as a particular form of facilitation, a key skill in environmental decision making (Ison et al. 2006);

2. join water management to flood management in the context of the SWB, something that has not been achieved in England and Wales even though both are the responsibility of the EA;

3. incorporate "integration" as a conceptual and practical feature of the legislation, e.g., sustainable flood management, promotion of integration between departments and organizations, a national-level committee for overseeing river-basin management plans; and

4. incorporate structures and processes in the legislation so as to ensure that commitments to participation are met, e.g., an annual review by Parliament of the management/ implementation of the SWB.

In all the NGO group “ ... drafted, I think, around 30 amendments to the bill to go forward to stage 2" (Interview SPC7). Another interviewee observed that, at the end, " the Minister came along to our event [after the Bill was passed] and said, 'Oh, I'm really proud.' It's something he could be proud of, it didn't matter whose name was on it in the end, it was a process of working together. We came up with something which we were all happy with, rather than us attacking his position and him attacking ours back, so it was much more useful to work together on it, and actually shift away from the status quo" (Interview SPC8b). What this interviewee was reporting was what we call social learning or concerted action by a range of stakeholders around an issue of concern (Figs. 1 and 2).

\section{CONCLUSIONS}

The SLIM (Social Learning for the Integrated Management and sustainable use of water) heuristic device (Figs. 1 and 2) can be used for sense making in relation to much of our data (Appendix 2), and in particular the story of the "bewitching" of the Scottish Water Bill (SWB). SLIM researchers recognize three ways to use the heuristic (SLIM Project 2004b): (1) as an observer observing a complex environmental management situation with an interest in understanding the factors at play, (2) as an enabler enabling the environmental policy- 
making process with an interest in identifying and helping to create conditions conducive to social learning, and (3) as an insider within a situation jointly reflecting upon an environmental management situation with other stakeholders who wish to gain a deeper and more comprehensive understanding of the situation in which they find themselves. In this case, we have used the heuristic in the first, i.e., the observer/researcher, mode.

Critical to the ability of the three witches to act in the way they did were aspects of the history and context, especially the peculiarities and distinctiveness of Scottish history compared to the rest of the UK and the fact that a new form of devolved government had recently been introduced to Scotland. The Water Framework Directive (WFD) and what it aspires to achieve in terms of ecological status, transparency, and public participation were also conducive conditions (Ollivier et al. 2007). Although, in principle, the WFD is a conducive policy context for social learning when contrasted with earlier EU directives, the emergence of the metaphor of no gold-plating created a climate of parsimony, particularly within the Department of Environment, Food and Rural Affairs and especially in England and Wales, inimical to innovative forms of stakeholder engagement, which were seen, without empirical justification, as too expensive. McClintock et al. (2004) demonstrate how metaphors reveal and conceal and thus constrain or enable changes in understandings and practices.

In the Scottish case, the issue of devolution was critical insofar as it increased the chances for polycentric management of resources by changing the existing boundaries of participation and facilitates engagement by stakeholders who had previously not been given a voice. Sources both inside and outside the UK have reported to SLIM researchers their admiration for what has, and is being, achieved in Scotland in regard to WFD implementation. It is clear that by taking decisive action, by reframing the no-gold-plating metaphor, and by organizing a wide-ranging stakeholder consultation process much has been achieved that is viewed positively by internal and external stakeholders. Scotland has benefited from having conducive institutional arrangements such as (1) the committee structure of the new devolved parliament; (2) the presence of an organization like Scottish Environment Link (SEL), a platform for a network of environmental NGOs and something that is not present in England; and (3) a relatively small heterogeneous population with strong networks. These are all factors that contribute to building relational capital (Appendix 5).

The NGOs also facilitated significant shifts in the domains to which another SLIM variable, ecological constraints, applied to incorporate wetlands, estuaries, and flooding. This exemplifies how boundaries lead to particular social constructions of ecological constraints. In conjunction with this, the three witches actively facilitated changes in understanding so that stakeholdings were built in these broader boundary judgments.

Our SLIM heuristic does not refer explicitly to power, but it is clear from our research that power relations changed, e.g., the loss of landowner access to the House of Lords. These changing power relations were opening up spaces for learning (see High 2000), but in our examples power is mediated by institutional arrangements and can thus be encompassed in the framework heuristic.

An important aspect of this story relates to the novel and effective way in which the NGOs worked together, i.e. their practices (Fig. 1). This was unique despite the existence of SEL. It was noted that they had not worked in this way on the Land Reform Bill, to which they were equally committed. It was suggested that the Scottish Water Bill started with a clean slate and that none of the main participating NGOs had a prior vested interest in a particular policy; this indicates how sensitive processes are to initial starting conditions, a particular aspect of the history of the situation. There is also a suggestion that operating as a team of three, with backup submissions on specifics from SEL member organizations, allowed the small group to focus on process more than content and to concentrate on broader themes. Although we have no evidence for this, it may also be that each member organization was able to maintain its own profile and enhance its own organizational status, which is necessary for attracting members, donors, and so forth, while committing to the SEL-facilitated activities, i.e. the institutional settings of participant organizations are as critical as the individuals who represent them.

The bewitching story exemplifies how a group of stakeholders can move toward concerted action, $i$. e., produce social learning through changes in understandings and practices. The challenge is how 
to replicate this in novel contexts and to invest in it as an alternative governance mechanism (Ison et al. 2007). In theoretical terms, we view this case as primarily exemplifying learning processes associated with single-loop learning. Argyris and Schön (1996) define single-loop learning as learning that changes strategies of action through the detection and correction of error, i.e., through a simple feedback loop. In contrast, double-loop learning is learning that results in a change in the values that inform the judgments upon which single-loop learning relies. Double-loop learning is often hard to achieve and may require theories in use that are reasonably uncommon (Argyris 1992). It also requires some commitment to reflection in and on action. Doubleloop learning was not apparent in this case and seems a prerequisite for replication and/or purposeful investment in social learning. We have found that using the heuristic in enabling or insider modes (see above) is one means of triggering double-loop learning and thus facilitating understandings that enable replication in other contexts (SLIM Project 2004b); this was not possible with this case study. Another way of looking at this theoretically is moving from participation to reification in the process of building communities of practice (Wenger 1998). In the water bill example, there was facilitated participation but no overall reflection that could have led to reifying this participation, i.e., making a "thing" of it such as a repeatable strategy.

Our research demonstrates how the policy context for water management in Scotland differs legally and culturally from that of the rest of the UK. It also revealed that the exact form that river-basin planning and thus catchment management will take is contested despite the existence of legislation. This situation exemplifies policy as process, the common circumstance in which policy is designed "to change a given situation but [where] the situation is changing anyway and giving rise to changing pressures for changes in policy" (Thomas 1998). The Water Environment and Water Services (Scotland) Act 2003 seems well equipped to deal with policy as a process because it envisages secondary legislation and the naming of a range of responsible authorities as well as an annual review process. The naming of SEPA as lead authority rather than as competent authority, as with the Environment Agency in England and Wales, is also more conducive to SEPA working with other agencies and stakeholders to implement the WFD. The alternative to policy as process is policy as prescription, which assumes, all too often, an unchanging context. Policy as process also depends on policy praxis, which in turn is dependent on the conceptual and practical skills of those charged with enacting the policy.

We conclude that the Scottish policy context over the period spent developing the SWB and beginning the implementation of the WFD was conducive to social learning. However, greater understanding of learning processes, associated learning theories and capacity building (SLIM 2004h), e.g. through the use of the SLIM heuristic, would seem to be important prerequisites for institutionalizing social learning as a complementary governance mechanism for the management of water.

Responses to this article can be read online at: http://www.ecologyandsociety.org/voll2/iss 1/art21/responses/

\section{Acknowledgments:}

We thank those who made time for interviews; we were received with openness and courtesy by all. We thank our SLIM colleagues for their support and contributions to our own learning and David Tàbara for his helpful editorial comments. The work reported from the SLIM project has been financially supported by the European Commission under contract number EVK1-CT-2000-00064(SLIM).

\section{LITERATURE CITED}

Argyris, C., 1992. On organizational learning. Blackwell Business, Cambridge, UK.

Argyris, C., and D. Schön. 1996. Organisational learning II: theory, method and practice. AddisonWesley, Reading, Massachusetts, USA.

Blackmore, C. P., and R. M. Morris. 2001. Systems and environmental decision making: postgraduate open learning with the Open University. Systemic Practice and Action Research 14(6):681-695.

Blackmore, C. P., K. Collins, P. Furniss, D. Morris, and M. Reynolds. 2004. The UK policy 
context for water management: I-the English and Welsh policy context. SLIM Case Study Monograph No. 12a. Available online at: http://slim.open.ac.uk/ objects/Outcomes/SLIM\%20CSM\%2012A\%20-\% 20England $\% 20$ and $\% 20 \mathrm{Welsh} \% 20 \mathrm{Policy} \% 20$ Context. pdf.

Collins, K. B., R. L. Ison, and C. P. Blackmore. 2005. River basin planning project: social learning (Phase 1). Environment Agency, Bristol, UK.

Glaser, B., and A. Strauss. 1967. The discovery of grounded theory. Aldine, Chicago, Illinois, USA.

High, C. 2002. Opening up spaces for learning: a systems approach to sustainable development. Dissertation. The Open University, Milton Keynes, UK.

Ison, R. L., C. P. Blackmore, and R. M. Morris. 2006. Starting off systemically in environmental decision making. Environmental Decision Making: a Systems Approach (T863), No. 2. The Open University, Milton Keynes, UK.

Ison, R. L., N., Röling, and D., Watson. 2007. Challenges to science and society in the sustainable management and use of water: investigating the role of social learning. Environmental Science \& Policy 10(6), in press.

Ison, R. L., and D. B. Russell, editors. 2000. Agricultural extension and rural development: breaking out of traditions. Cambridge University Press, Cambridge, UK.

Ison, R. L. and D. Watson. 2004. The UK policy context for water management: II-the Scottish policy context. SLIM Case Study Monograph No. 12b. Available online at: http://slim.open.ac.uk/obj ects/Outcomes/SLIM\%20CSM\%2012B\%20Scottish\% 20Policy.pdf.

Kaïka, M. 2003. The Water Framework Directive: a new directive for a changing social, political and economic European framework. European Planning Studies 11(3):299-316.

Kaïka, M., and B. Page. 2003. The EU Water Framework Directive. Part 1: European policymaking and the changing topography of lobbying. European Environment 13(6):314-327.

Leeuwis, C., and R. Pyburn, editors. 2002. Wheelbarrows full of frogs: social learning in rural resource management. Koninklijke van Gorcum, Assen, The Netherlands.

McClintock, D., R. L. Ison, and R. Armson. 2004. Conceptual metaphors: a review with implications for human understandings and systems practice. Cybernetics and Human Knowing 11(1):25-47.

Mehta, L., M. Leach, P. Newell, I. Scoones, K. Sivaramakrishnan, and S. Way. 1999. Exploring understandings of institutions and uncertainty: new directions in natural resource management. IDS Discussion Paper No. 372. Institute of Development Studies, Brighton, UK.

North, D. 1990. Institutions, institutional change and economic performance. Cambridge University Press, Cambridge, UK.

Ollivier, G., M. S. Barzman, and P. Steyaert. 2007. A systemic, analytical understanding of the Water Framework Directive questioning its potential to enable sustainable management of water. Ecology and Society 12(1), in press.

Page, B., and M. Kaïka. 2003. The EU Water Framework Directive. Part 2: Policy innovation and the shifting choreography of governance. Available online at: http://209.85.165.104/search?q=cache: v0ortf5dq0QJ:www.geog.ucl.ac.uk/ bpage/files/ EuropeanEnvironmentpart2.pdf+Page+Part $+2+\%$ 22Water+Framework+Directive $\% 22 \&$ hl=en\&ct= $\underline{\mathrm{clnk} \& \mathrm{~cd}=1 \& \mathrm{gl}=\mathrm{ca}}$.

Patton, M. Q. 1987. How to use qualitative methods in evaluation. Sage, Thousand Oaks, California, USA.

Röling, N., and A. Wagemakers, editors. 1998. Facilitating sustainable agriculture: participatory learning and adaptive management in times of environmental uncertainty. Cambridge University Press, Cambridge, UK.

SLIM Project. 2004a. Introduction to SLIM publications for policy makers and practitioners. Available online at: http://www.transboundarywater. se/documents/SLIM/Slim\%20introduction.pdf.

SLIM Project. 2004b. SLIM framework: social learning as a policy approach for sustainable use of water. Available online at: http://www.transboun darywater.se/documents/SLIM/Slim\%20introduction. pdf. 
SLIM Project. 2004c. Stakeholders and stakeholding in integrated catchment management and sustainable use of water. SLIM Policy Briefing No. 2. Available online at: http://slim.open.ac.uk/objects/ public/slim-pb2-final-screen.pdf.

SLIM Project. 2004d. Facilitation in policy processes: developing new professional skills. SLIM Policy Briefing No. 4. Available online at: http://slim.open.ac.uk/objects/public/slim-pb4-finalscreen.pdf.

SLIM Project. 2004e. Developing conducive and enabling institutions for concerted action. SLIM Policy Briefing No. 3. Available online at: http://sl im.open.ac.uk/objects/public/slim-pb3-final-screen. pdf.

SLIM Project. 2004f. The role of conducive policies in fostering social learning for integrated management of water. SLIM Policy Briefing No. 5. Available online at: http://slim.open.ac.uk/objects/p ublic/slim-pb5-final-screen.pdf.

SLIM Project. 2004g. The role of learning processes in integrated catchment management and the sustainable use of water. SLIM Policy Briefing No. 6. Available online at: http://slim.open.ac.uk/o bjects/public/slim-pb6-final-screen.pdf.

SLIM Project. 2004h. Guidelines for capacity building for social learning in integrated catchment management and the sustainable use of water. SLIM Policy Briefing No. 7. Available online at: http://sl im.open.ac.uk/objects/public/slimpb7final.pdf.

Steyaert, P., and J. Jiggins. 2007. Governance of complex environmental situations through social learning: a syntehsis of SLIM's lesson for research, policy and practice. Environmental Science and Policy 10(6), in press.

The Open University. 2004. Managing complexity: a systems approach. The Open University, Milton Keynes, UK.

Thomas, A. R. 1998. Introduction. Pages 1-18 in A. R. Thomas, J. Chataway, and M. Wuyts, editors. Finding out fast: investigative skills for policy and development. Sage, Thousand Oaks, California, USA.

Van de Fliert, E., 1993. Integrated pest management. Farmer field schools generate sustainable practices: a case study in central Java evaluating IPM training. WU Papers No. 93-3. Wageningen Agricultural University, Wageningen, The Netherlands.

Wenger, E. 1998. Communities of practice: learning, meaning and identity. Cambridge University Press, Cambridge, UK. 


\section{Appendix 1. Interview Details.}

Table A1-1. Details of semistructured interviews conducted for this research.

Interviewee's affiliation

Scottish National Heritage $(\mathrm{SNH})$

Association of Salmon Fisheries Boards

Freshwater Fisheries Laboratory, Faskally, Pitlochry

Forestry Commission

Scottish Environment Link (SEL)

Scottish Environment Link and Scottish Wildlife Trust

Scottish Environmental Protection Authority (SEPA)

SEPA

Glasgow and Clyde Valley Core Team (Planning)

SEPA Board

Scottish Executive

SEPA

SEPA
Date/interview type

9 January 2003/individual

15 April 2003/individual

13 January 2003/group (three)

13 January 2003/group (three)

14 April 2003/individual

14 April 2003/group (pair)

28 March 2003/individual

28 March 2003/individual

14 April 2003/individual

15 April 2003/individual

27 May 2003/group (three)

10 January 2003/individual

9 January 2003/group (pair) 


\section{Appendix 2. Themes and Subthemes.}

Table A2-1. The main themes and subthemes to emerge from the Scottish policy context case study, the source for naming these themes/subthemes, and the main SLIM variables that are illuminated by a subtheme.

\begin{tabular}{llll}
\hline \hline Theme title & Subthemes & $\begin{array}{l}\text { Main source of } \\
\text { subtheme }\end{array}$ & $\begin{array}{l}\text { Main variables in the SLIM } \\
\text { heuristic illuminated by } \\
\text { theme }\end{array}$
\end{tabular}

History of water

management situation in

Scotland

Ecological and water management issues shaping practices

The Water Framework Directive (WFD)

\section{N.A.}

Desk study supplemented by interview data

Interviewee- and other stakeholder-nominated themes

Ecological constraints

Land management practices

Forestry and acidification

Agriculture

Upland grazing

Origins of the WFD: a perspective from Scotland

Is the WFD a sectoral policy despite its holistic intent?

Does the WFD enshrine a set of processes that, at the end of the day, can only be resolved by human judgment about the "Nature" we construct?

Has the translation of the WFD into an implementation strategy established organizational "silos?"

Implementing the WFD: Will the implementers be prepared to proceed in such a way that it can be seen as a learning process open to adaptation and change?
Researcher-derived themes History of situation from interviews, except for first subtheme, which was primarily interviewee-nominated Ecological constraints 
The "bewitching" of the Scottish Water Bill

River basin management planning in Scotland: prospects
Building stakeholding

The gold-plating metaphor

Exploiting the legislative process

The significance of the committee structure in the Scottish Parliament

Facilitation

Integrating institutional arrangements

Changes that were achieved: judging effectiveness
Interviewees and researcher

History of situation

Institutions and policies

Ecological constraints

Facilitation

Stakeholders and stakeholding
Policy as praxis: the threat of technical and instrumental rationalities

Establishing sub-basins in Scotland

Doing river basin management planning
Researcher-derived from History of situation interviews

Institutions and policies

Ecological constraints

Facilitation

Stakeholders and stakeholding

Interviewees and researcher

Integration with agriculture

Integration of flooding and river basin planning

Skills and capacity

Participation and integration

Integration as praxis

Emerging platforms associated with water

Promising platform configurations and processes
Interviewees and desk Institutions and policies research Researcher-derived from History of situation interviews

Stakeholders and stakeholding 
Other emergent themes

The role of science and scientists
Identity and place: social research
Interviewees and researcher
Ecological constraints

Stakeholders and stakeholding 


\section{Appendix 3. The Bewitching of the Scottish Water Bill.}

Key learning events and processes in the "bewitching" of the Scottish Water Bill (SWB) included:

1. the field trip to Insh Marsh. "The Committee members said that was a really useful research experience. They actually said that, and many of them made reference to it at either Stage 2 or at Stage 3, and the fact that we did, and that they really saw it for themselves and realizing that the wetlands really matter. Trying to sell to politicians that wetlands really matter was like a nightmare, but actually in the end, them seeing this huge sponge and [that] Aviemore will be washed away without it, really made such a difference. In amending the bill, they really felt that they could identify what this meant, and I think that's probably why the wetlands stuff got through" (Interview SPC7).

There is clearly a strong relationship between the concept of relational capital and what is experienced as trust. It was suggested that " ... if people are in the business of establishing trust and having as leisurely [a] debate as they can, it's easier to do in the devolved situation than it ever was when any legislation like this would have had to have gone through Westminster, and I think, because of the effect of devolution, the civil servants' attitudes have had to change" (Interview SPC3).

From the NGO perspective, the field trip “ ... almost worked too well. The civil servants have been clamoring to go on a similar trip [to another site in relation to another issue], so the planning and the water guys just went up last week, a coach load of Scottish Executive Officials from two different buildings, and planning and water people from within Link, and agriculture people from within Link as well." Importantly, the success of the initial experiential event has left a praxis legacy.

2. introducing external perspectives. Events were held just before the SWB was reconsidered and before the summer and in June of 2002. These were considered " ... useful as well, because it opened up other perspectives that they had not thought of, with some really quite good contributions from Denmark, but also on the insurance aspect for flooding and that really hit home with the MSPs [members of the Scottish Parliament], but again a lot of them said to me afterwards, 'That was a very useful and interesting event,' and it got them thinking about the bill" (Interview SPC8).

3. modeling, through action, the language they were using. The NGO staff recognized the need to get people involved early and to practice what they were preaching. Through this process, the perspective of civil servants changed from thinking along the lines of, "Oh, this is the environmentalist saying, 'Participation for participation's sake,' to thinking, 'there was a real learning process went on there" (Interview SPC7). It was more than providing information; the experiential nature of engaging stakeholders enabled them to experience the issues that were at stake.

4. systems thinking. Systems thinking was part of their repertoire, although it is unclear to what extent thinking and acting systemically was done consciously. "Link as a group was able to say, 'We need to be a bit more creative about how we're thinking about dealing with floods and whatever,' other than building masses of concrete. We think this is a system and that wetlands are part of this system, and we have to build them into that. The systems are fascinating, actually. Dealing with the MSPs, real systems thinking, getting them thinking ...” (Interview SPC7). 


\section{Appendix 4. Features of the Scottish Legislative Process.}

In Scotland, the conduct of the public consultation element of bills has taken two forms. "Sometimes they produce a draft bill that is then consulted on, and it's actually laid out like a bill. But sometimes they produce proposals for consultation, which just say, 'This will be in the bill, and this won't be in the bill, and, according to our consultation, this is what should be in the bill.' With the second option, it's very much more difficult to tell what will be in the final bill before it goes to Parliament." This second strategy was adopted by the Executive. "At that stage, when evidence was being submitted, we were aware that the people who we felt might submit evidence to it, like the farmers [and] others, were quite obviously missing" (Interview SPC7). From the perspective of this interviewee, this was unsatisfactory "because it was such a wide-ranging bill" (Interview SPC7).

Respondents described a three-stage process associated with the introduction of bills:

1. Stage 1 , involving wide-ranging consultation, looks at the general principles of the bill, the scope of the bill, and whether the bill, as it's titled and laid out, meets what it's objectives are, when the bill is introduced to Parliament.

2. Stage 2 goes into more detail in committee, when all the information from Stage 1 has been put together in a report on general principles that has been voted on by Parliament.

3. Stage 3 allows for last-minute amendments when the bills goes back to chamber for a long debate after Stage 2, after which a decision is made on whether or not the bill should be passed and become an act.

Under the Scottish Parliament structure, there is no second chamber, so there is no review chamber as there is in the House of Lords in Westminster, and the compensation has been that the select committees are much more powerful. "They're [the Committees] the ones who really steer legislation through Parliament, so it's a different system from Westminster. Select committees [play] much more of an advisory critical role, so they all trade to the select committees. The system is designed to be more transparent and more accessible for people to get involved in" (Interview SPC7). This respondent, reflecting on the first four years of operation of the Scottish parliament, claimed that "people definitely feel that the committees are doing that job, opening it up for others to participate much more. And in the chamber amending exercise on every bill, it's quite an open debate, and we have others involved, which is good" (Interview SPC7). 


\section{Appendix 5. Relational Capital.}

In water management, integration, in the sense of integrated catchment management, is usually a key concern. Following SLIM (2004f), we argue that integration must concurrently value the expression of local needs and interests through a bottom-up approach. In a knowledge-based society, people should be recognized for what they do and not just for what they are, i.e., their recognized status should be that of subjects, not objects. The added value of such an approach is the emergence of relational capital resulting from the presence and interactions of different elements of the other forms of capital, namely, natural, social, artificial, and human. The involvement of citizens, formal groups, enterprises, and institutions that share the same concerns facilitates the integration of sector-specific policies. However, these shared concerns can only become explicit when they are derived from collaborative knowing. The emergence of relational capital results from the presence and interactions of different elements of the other forms of capital. 